\title{
Disruptive Technologies for Labor Market Information System Implementation Enhancement in the UAE: A Conceptual Perspective
}

\author{
Ghada Goher ${ }^{1}$, Maslin Masrom², Astuty Amrin ${ }^{3}$, Noorlizawati Abd Rahim ${ }^{4}$ \\ Razak Faculty of Technology and Informatics, Universiti Teknologi Malaysia
}

\begin{abstract}
In December 2019, the world learned about the first outbreak of the novel coronavirus (COVID-19) that first broke out in Wuhan, China. This limited outbreak in a small province of China has rapidly evolved into a global pandemic that has led to a health and economic crisis. As millions of individuals have lost their lives, others have lost their jobs due to the recession of 2020 . While the skills and educational mismatch have been a prevalent problem in the UAE labor market, it is logical to assume that the global pandemic has likely increased this problem's extent. Therefore, there is an urgent need to adopt an agile, innovative solution to address the upcoming challenges in the labor markets due to the lack of skilled resources and the fear of future work amid the COVID-19 pandemic. Since industry and academia have identified skills and educational mismatch as a complex and multivariate problem, the paper builds a conceptual case from a system engineering perspective to solve this problem efficiently. Based on the literature reviewed related to disruptive technologies and labor market management systems, the paper proposes a new implementation approach for an integrated labor market information system enabled by the most widely used disruptive technologies components in the UAE (Machine Learning, AI, Blockchain, Internet of Things, Big Data Analytics, and Cloud Computing). The proposed approach is considered one of the immediate course of actions required to minimize the UAE economy's negative impact due to the presence of the skills and educational mismatch phenomena.
\end{abstract}

Keywords-Disruptive technologies; labor market information systems; skills and educational mismatch; future of work; system engineering; system design thinking; COVID-19

\section{INTRODUCTION}

The global COVID-19 pandemic has led to a complete transformation of the status quo and has challenged the current living and business landscapes. The ripple effects of the global pandemic hit all economic sectors in all countries. Under the current crisis, one aspect that has become clear is that there is a need to deploy disruptive technologies to solve common problems such as remote working, which exacerbated due to the need to keep the social distance. The current paper focuses on the skills and educational mismatch, one of the ever-lasting and continuously increasing problems in the UAE's labor market [1-3]. Since it is a large-scale problem, UAE policymakers need to ensure that they are taking the appropriate steps towards disruptive technologies deployment while thinking about a solution to this problem. Despite that, the utilization of disruptive technologies penetrates the current processes and the paradigms that are followed [4]; the current practices of labor market information system (LMIS) implementation in the UAE has not yet leveraged such technologies. Therefore, proper utilization of disruptive technologies can potentially enhance the LMIS implementation practices and enable the UAE to solve the national mismatch problem for a better future of work. Such utilization will enable feasible development for an agile, innovative solution for such a complex problem and offer intelligent collaborations and workflows. From the other side, on a country level, labor market information systems are the most recommended solutions for better management of the labor markets as such solutions enable the identification and the collection of different types of information from the multistakeholders involved. With these in mind, the current paper is building a conceptual case to improve the future of work in the UAE labor market amid COVID-19 by potentially implementing an integrated labor market information system enabled by disruptive technologies.

The paper begins with a review of the concept of disruptive technologies and their various types while highlighting the opportunities that the technologies offer towards enabling the efficient development of complex solutions. Then, the paper presents an understanding of the Labor Market Information Systems (LMIS) and identifying their primary purposes for better labor market management. Following that, the paper portrays the mismatch outlook in the UAE labor market and the need for iLMIS implementation to resolve this issue. In addition, an explanation for the current trend for iLMIS implementation is provided, along with its limitations. Hence, a strategic course of actions is proposed to forward a better future of work in the UAE labor market amid COVID-19. Lastly, challenges and future guidelines will be discussed.

\section{DisRUPTIVE TECHNOLOGIES}

As all technology innovations can be considered disruptive, the list of disruptive technologies is increasing almost always. However, some technological innovations can transform the value pools and individuals' status quo in business and social landscapes. Therefore, countries need to be able to identify the scope of new technologies and the impact that they are going to have on people's lives and prepare accordingly. For this reason, it is rational to start the discussion with a quick review of the disruptive technologies. As identified by [4], disruptive technologies are classified as human-centric and smart-spacebased technologies. Table I summarizes the stated types of disruptive technologies, along with their supporting emerging technologies, as outlined by [4]. 
TABLE I. CATEGORIZATION OF TECHNOLOGY

\begin{tabular}{|l|l|l|}
\hline $\begin{array}{l}\text { Disruptive } \\
\text { technology } \\
\text { theme }\end{array}$ & $\begin{array}{l}\text { Disruptive } \\
\text { technology types }\end{array}$ & Supporting emerging technologies \\
\hline \multirow{4}{*}{$\begin{array}{l}\text { Human } \\
\text { Centric }\end{array}$} & Hyper-automation & Machine Learning, Robotics \\
\cline { 2 - 3 } & Multi-experience & $\begin{array}{l}\text { Virtual reality (VR), augmented reality } \\
\text { (AR), and mixed reality (MR) }\end{array}$ \\
\cline { 2 - 3 } & Democratization & Big Data Analytics \\
\cline { 2 - 3 } & $\begin{array}{l}\text { Human } \\
\text { Augmentation }\end{array}$ & $\begin{array}{l}\text { Virtual Reality, Augmented Reality, } \\
\text { Virtual Assistants, Computer Vision, } \\
\text { Biometrics }\end{array}$ \\
\cline { 2 - 4 } & $\begin{array}{l}\text { Transparency and } \\
\text { Traceability }\end{array}$ & Blockchain and Big Data Analytics, 5G \\
\hline \multirow{5}{*}{$\begin{array}{l}\text { Smart } \\
\text { Space }\end{array}$} & Empowered edge & Internet-of-things, Big Data Analytics, 5G \\
\cline { 2 - 4 } & Distributed Cloud & Cloud Computing, Big Data Analytics \\
\cline { 2 - 3 } & $\begin{array}{l}\text { Autonomous } \\
\text { things }\end{array}$ & $\begin{array}{l}\text { Drones, autonomous vehicles, robotics, } \\
\text { 5G }\end{array}$ \\
\cline { 2 - 3 } & $\begin{array}{l}\text { Practical } \\
\text { Blockchain }\end{array}$ & Blockchain \\
\cline { 2 - 3 } & AI Security & Artificial Intelligence, Blockchain \\
\hline
\end{tabular}

(Source: 4)

\section{A. Human-Centric based Technologies}

Human-centric technologies are one of the most transformative and impactful technologies at the individual level, whereby these technologies are intended to cater to the user's evolving needs. These technologies also define the interaction between users and the digital world. Some of the core types of these technologies include hyper-automation, multi-experience, democratization, human augmentation, as well as transparency and traceability [4].

Hyper-automation is a human-centric technology; it is a combination of several machine-learning techniques. It efficiently enables processes' automation and humans' augmentation. Moreover, it covers all the automation steps, including; discovering, analyzing, developing, implementing, monitoring, and re-assessing [5-6]. This type of technology includes two primary components: robotic process automation and intelligent business process management suites. The benefit of robotic process automation is enhancing the shortterm processes and works by eliminating repetitive tasks using data manipulation and an integrated script structure that is tightly defined. Therefore, it facilitates the shift from legacy systems to new ones. While, the intelligent business process management suites help enhance the long-term processes and works as they also provide a unified solution that orchestrates between people, processes, and things. It is also a collection of tightly defined rules that can be used to oversee contextual work with its most common application to support the full life cycle of any processes end-to-end.

Furthermore, multi-experience technology provides users with different experiences and a new platform to interact with the digital world [4]. For example, technologies such as virtual reality, augmented reality, and mixed reality provide users with a multimodal sensory experience that can virtually deliver the relevant information and desired actions for different system users [7-8].
Besides, democratization is the technology that facilitates equally easy access to end-users (both potential and native) as well as expertise users (both discipline and domain) [4]. Such access facility is provided by using revolutionary technologies that can provide end-users with access to systems and information while needing minimal training. The technology of democratization uses artificial intelligence while developing a solution; this ensures that as time passes, the cost of the development of new solutions reduces and its production increases while supporting the developed solutions to run automatically based on the different users' interventions.

Human augmentation is defined as a technology that enhances human experience using physical and cognitive components. It offers humans many opportunities to develop their capabilities which contribute directly to a better condition. For instance, physical augmentation technologies provide humans with wearable devices that can enhance their physical bodies' capabilities, such as senses and biological functions [9]. On the other hand, cognitive augmentation technologies enhance human skills for better learning, development, and decision-making [10].

Lastly, transparency and traceability are defined as the ward that ensures trust, transparency, and ethics are addressed while disruptive technologies are used [11-12]. One of the core methods to restore trust is through paying attention to three areas while developing new systems powered by disruptive technologies: the use of AI, the use of personal data (privacy, control, ownership), and the use of a design that is ethically compliant [12].

Hence, Human-centric based Technologies are efficiently used in the case of complex systems development, especially in the case of customized profiling, distance collaboration between different users, and iterative enhancement of workflows are required.

\section{B. Smart-Space based Technologies}

Smart-space-based technologies connect different working environments and develop smart environments rich in information and provide context-specific intelligent services to different users [13]. It covers designing, implementing, and evaluating new information domains supported by new architectures to enable user-based intelligent services. There are several types of smart-space-based technologies such as edge computing, distributed cloud, autonomous things, practical blockchain, and AI security.

Edge computing is referred to as the technology that brings the computing and storage of data close to each other, significantly reducing bandwidth usage and enhancing response times when needed [14]. Therefore, it is predicted that approximately $50 \%$ of the companies will shift to edge computing from cloud computing [4].

The distributed cloud is also an advanced cloud computing technology that uses data storage at different geographic locations, enabling the distribution of service operations at these locations with the well-defined operation, governance, and evaluation of these distributed services. It operates under a tightly coupled system that has storage, computation, and networking capabilities. It is different from edge computing as 
it is establishing a distributed cloud that provides closer data processing computing to the end-user, decreased latency, processed data, and enhanced security in a real-time environment.

On the other hand, autonomous things are inter-connected and AI-enabled physical devices. They are designed to replace humans; this includes robots, autonomous vehicles, and appliances. In essence, it is an enhanced level of automation as these devices deliver smart services to users. This technology's growth shall pave a pathway to shift from stand-alone intelligent systems to collaborative intelligent systems [15].

Moreover, a practical blockchain is a secure distributed ledger containing a chronological list of unalterable transactions records. These transactions can also be traced back to their origin, which makes them completely secure. Therefore, blockchain technology conveys trust, transparency, values and empowers collaborations across different digital eco-systems. However, blockchain is not scalable due to technical deficiencies and interoperability issues; thus, preventing it from being widely used in the business context [16].

Lastly, AI security. Based on the fact that artificial intelligence rapidly integrates into human decision-making and plays a crucial role in individuals' everyday lives, which has been facilitated due to the presence of the internet of things, cloud computing, and micro-services, along with the fact that individuals are increasingly connected. Therefore, with this level of penetration of artificial intelligence, there is a need to ensure that the safety, protection, and security defense of the AI-powered systems protect the individuals' data from cyber attackers.

Hence, smart-space-based technologies can be efficiently used as infrastructure in complex systems development, especially if required, for such development, to connect different working environments at different geographic locations to offer smart services with enhanced security to different users.

From amongst these advanced technologies outlined above, a total of six disruptive technologies have found widespread application in the UAE: Machine Learning, AI, Blockchain, Big Data, IoT, and Cloud Computing. The author in [17] noted that the UAE had established the groundwork for machine learning and AI learning by developing policies and providing incentives to drive their application. Furthermore, blockchain has also found widespread use in the UAE, with the public sector increasingly using blockchain to conduct its transactions [18]. Similar trends are noted in the UAE concerning big data analytics, whereby Dubai's Smart City Strategy is a big dataenabled program whereby big data analytics is poised to become a leading-edge technology in the UAE [19]. In addition, in terms of IoT, the application of this technology in the UAE is widespread, to extend that there is a new regulatory policy for the use of IoT in the country [20]. Finally, concerning cloud computing, an increase in usage is seen whereby there has been a surge in cloud computing use in the UAE in the past few years [21]. Therefore, these technologies that have widespread use in the UAE have been selected in this paper to build the conceptual case.

\section{LABOR MARKET INFORMATION SYSTEMS (LMIS)}

A labor market information system is a set of foundations (government and private, workforce, employers, citizens) connected and collaborated to maximize the labor market's potential. Such effective management of the labor markets achieved as LMIS performs the identified roles and responsibilities for the production, storage, dissemination, and use of labor market data for better policy and program formulation and implementation.

Labor market information (LMI) is used as an umbrella term that represents all information related to the labor market, which includes the details of the labor supply and demand sides (structure, characteristics, and dynamics), as well as the information on lack of a labor market equilibrium. LMI exists in both "hard" (i.e., quantitative data and statistics) or "soft" (i.e., qualitative data on the functioning and characteristics of both labor market sides) forms.

In order to analyze the labor market and find the best information available regarding the state of the labor market, the collected raw data (both soft and hard) related to the labor market needs to be processed and transformed into what is called labor market intelligence [22, p. 4]. As illustrated in Fig. 1, LMI has three components; the input (labor market data), the process (labor market analysis), and the outputs (labor market intelligence).

Labor market information has four primary purposes:

1) Intervention-oriented, where LMI supports stakeholders to improve, resolve issues of the labor market.

2) Observation-oriented, where LMI serves labor market researchers to contribute to the economy and society's scholarly work.

3) Demand-oriented, where LMI increases employers' ability to hire the workforce efficiently.

4) Supply-oriented, where LMI offers a workforce, continues development to reduce the risk of exiting from the labor market.

Due to the complexity of the labor market management, the four purposes mentioned above of labor market information should be fulfilled; therefore, an LMIS must be comprehensive to provide value to all labor market stakeholders (i.e., policymakers, researchers, employers, and workforce).

As observed by [23], this compressive LMIS are generally catering one of the two following functions as presented in Fig. 2.

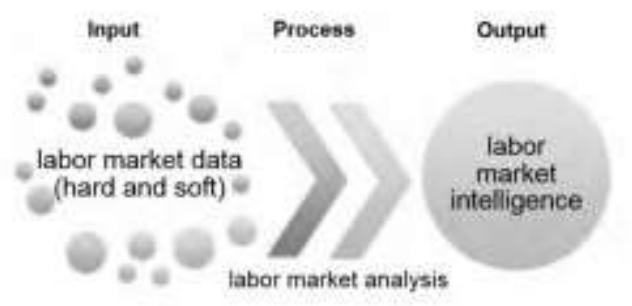

Fig. 1. The Components of Labor Market Information. (Source: 23). 

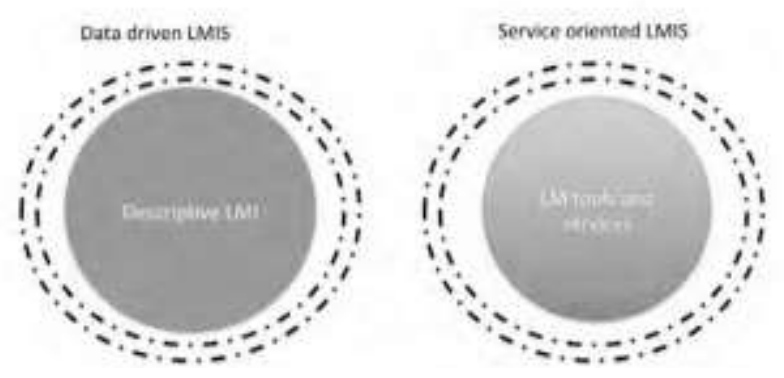

Fig. 2. Separated LMIS Functions. (Source: 23).

1) Data-driven LMIS: provides descriptive data on the labor market, mostly for the aim of intervention or observation. These systems build a set of statistical indicators such as unemployment rates, new job creation in a different sector, labor market demographics.

2) Service-oriented LMIS: provides labor market services to both sides of the labor market (demand and supply) to enhance their efforts to improve the work situation or the workforce, accordingly.

The author in [23] argued that instead of using separate functions of LMIS, an integrated LMIS (iLMIS), as illustrated in Fig. 3, should empower the labor market intelligence and analysis. Such integration for both functions shall identify more compressive LMIS implementation potentials representing the best solution for better labor market management, wherein data, policies, processes, and services are interlinked.

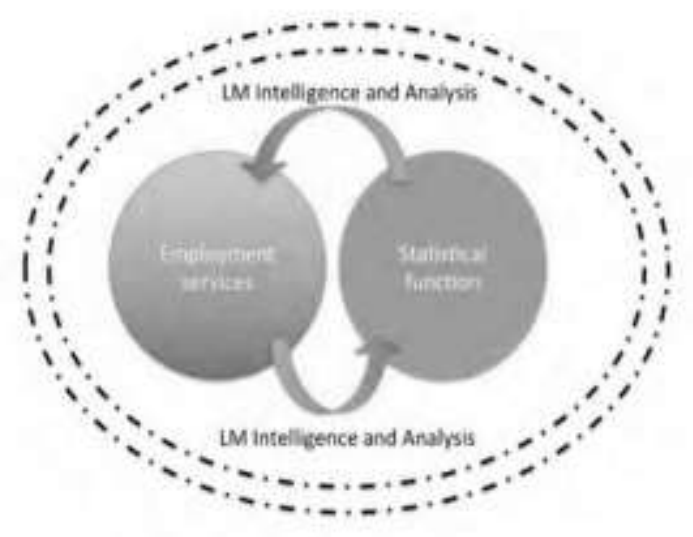

Fig. 3. Integrated LMIS (iLMIS). (Source: 23).

However, [23] did not consider the technology part for the feasible implementation of such a concept, iLMIS, neither the tools that allow for better gathering, processing, and disseminating labor market information. Hence, this paper proposes to complement this part by utilizing the wide applications offered by disruptive technologies.

\section{A. Need for Integrated LMIS in the UAE Labor Market}

Rapid technological advancements in the UAE have brought about a change in the status quo [24]. This technological change has not only replaced low-skill jobs but has also substantially transformed high-skill positions such as leadership, for instance. In other words, digital skills and knowledge of IT systems are crucial across all positions in an organization. In the UAE, which has transformed into the hub of rapid technological advancements and emerging technologies, skills and educational mismatch phenomena have become more prevalent in the labor market [25]. This phenomenon can negatively impact the country economy and employee-level outcomes [3], which is why there is a need to resolve the skills and educational mismatch problem.

Skills mismatch is defined as misalignment between the skills required by the employer and those possessed by the employee [26]. There are three types of skills mismatch: skill gap, shortage, and obsolescence. A survey revealed a predominant skills gap in the UAE labor market based on the research conducted by [3]. The same survey found a difference between what is expected from the demand side (the employers) and what is available on the supply side (the workforce). The author stipulated that one of the reasons for this difference was the lack of appropriate skills provision during the individual's education. Besides, this prevalence of skills gap in the UAE is deepened due to the rapid changes in the demand requirements; this is due to the new skills needed by the current unprecedented technological era, Industry 4.0, which is characterized by automation, advanced technology, and rapid change [24].

On the other hand, educational mismatch is defined as the incongruity between an individual's education and what is required by the job. The educational mismatch is generally of two types: horizontal and vertical mismatch. The horizontal mismatch is the difference between the individual's educational qualification and what is required by the job. While the vertical mismatch is the difference between the levels of educational qualification that an individual possesses and what is required by the job [27]. In the UAE context, [3] has identified a vast educational mismatch evident in the market, with horizontal mismatch being highly prevalent in the country relative to vertical mismatch. In other words, the authors have identified that there is a vast majority of individuals who are working in areas that are different from their field of education. One of the primary reasons that the authors identified to account for this educational mismatch in the UAE was that there is no alignment between what is required by the labor market demand (The employers) and what is supplied by the labor market suppliers (The higher education institutes).

Although the study by [3] offered an understanding of the predominance of skills and educational mismatch and its possible types in the UAE, there are limitations and disadvantages to the points highlighted as changes (seen and unseen) continuously reshape and unbalances the labor market. As a result, there is a need to understand the extent of skills and educational mismatch in the UAE and propose a feasible solution to solve this dynamic problem. Due to the COVID-19 pandemic, the overall frequency of job loss and economic downturn is much worse; therefore, the need to resolve the skills and educational mismatch becomes a matter of urgency to be fulfilled.

Therefore, to adequately address the highly prevalent skills and educational mismatch in the UAE's labor market and 
effectively manage the unforeseen risks, there needs to develop a solution that can mitigate the vast and complex problem of skills and educational mismatch. This solution must consider a new relationship model between the known labor market's stakeholders while considering the working relationship's new norm, working from different geographic locations.

\section{B. Current Trend for Implementing an Integrated LMIS}

The implementation of iLMIS should benefit all stakeholders, individuals, businesses, educational institutions and government bodies. The primary purpose of the iLMIS implementation is to support the decision-making process for all stakeholders at different levels by ensuring that timely and relevant labor market information is provided. Hence, an implementation of iLMIS necessitates the integration, automation, and presentation of labor market information to all stakeholders. Therefore, the iLMIS implementation requires identifying infrastructure requirements, associated costs, governance needs, and potential features. In addition, the implementation needs to ensure that the iLMIS platform is deployed in a sustainable, secure, user-friendly, efficient, and easy to access way.

Fig. 4 illustrates a design-thinking framework that addresses the various general modules required for an iLMIS platform through the avenues of its integrated modules and data source owners.

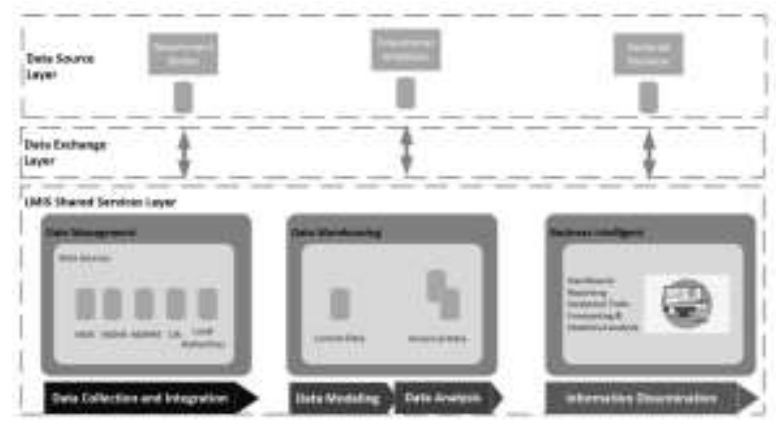

Fig. 4. Design Thinking Framework.

While Fig. 5 illustrates the ICT System Architecture of the current trend for an iLMIS infrastructure implementation.

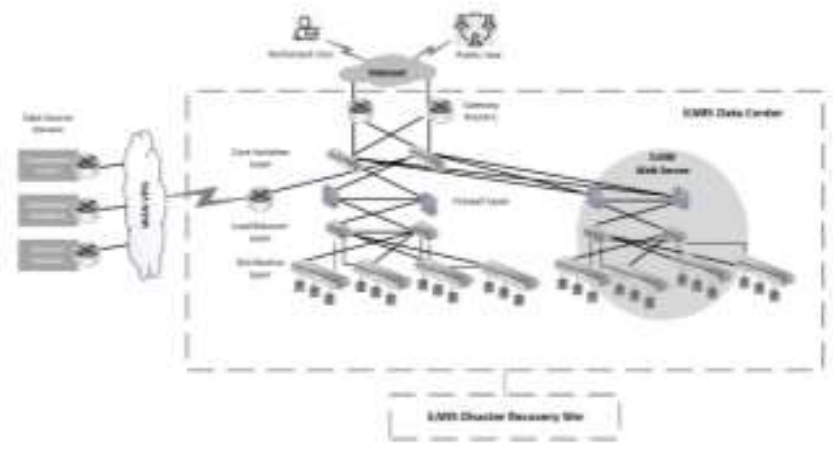

Fig. 5. ICT System Architecture of the Current Trend for iLMIS Infrastructure Implementation.
The current ICT infrastructure implementation approach focuses mainly on integration to route data from its sources through a secured wide area network (WAN-VPN) to be centrally hosted, analyzed, and interpreted. It requires the physical presence of a data center site (DC) as a focal point. DC is used to hosts applications, servers, security, load balancing, and data storage infrastructures. The data center is considered a hub that is accessed via the internet by all iLMIS users. A disaster recovery site (DR) is another physical location required for the recovery or continuity of the iLMIS operation in case of any disaster that happened to the DC, whether it is caused by natural or human. The iLMIS is implemented as a web-enabled platform that allows the authorized user and the job seekers to access the intranet systems at the DC, such as services, servers, applications, and databases.

One of the primary limitations of the current iLMIS implementation approach is that it does not consider the full lifecycle of the education-to-employment process end-to-end. There is a lack of orchestration between people, processes, and things. As shown in Fig. 4 and 5, there is increased fragmentation and lack of rightful ownership of the services, data, processes, and things. In addition to the lack of updated data from its sources, data owners are reluctant to share data. Therefore, it is challenging for such iLMIS implementation to understand proactive measures' principal characteristics without local and global data availability.

Furthermore, although the information or actions that different system users need do vary, the current iLMIS implementation approach does not provide a customized experience. Additionally, the current approach does not allow for developing a smart environment from different integrated environments. Moreover, in the current approach, it is not feasible to provide any real-time support to all stakeholders, as the computing and data storage do not co-exist in the same location. Also, the current approach does not support the transaction records' traceability, which limits the collaboration between stakeholders. Finally, the current approach does not facilitate smart, fast, and analytics-driven decision-making data.

Therefore, it is required to discover an efficient approach that supports a complex infrastructure implementation of an iLMIS. The new approach needs to enable connecting different working environments, distance collaboration, interactive workflow, intelligent services, and customized profiling.

\section{The Solution to a Better Future of Work}

Since the COVID-19 pandemic has started, disruptive technologies such as artificial intelligence, cloud computing, and the internet of things have been used for many purposes [28]. The author has outlined the use of disruptive technologies for saving human lives, increasing the understanding of the novel coronavirus disease, and enabling humanity to defeat the virus [28]. Furthermore, artificial intelligence has been called in for crisis management and national emergency during the pandemic. Besides, disruptive technologies have also been used to tackle sources of misinformation and generate reliable scientific information, as well as for assisting researchers in genome sequencing of the virus [29-31]. 
This widespread use of disruptive technologies can be extended to mitigate the skills and educational mismatch problem. The phenomenon of skills and educational mismatch is highly complex and multifaceted and hence, requires an equally powerful and complex solution structure that targets all the factors that are increasing skills and educational mismatch in the labor markets [3]. The study by [3] served as an exploratory study and did not provide a comprehensive insight into the possible solution for mitigating skills and educational mismatch problems. However, the authors state that emerging technologies need to be considered in developing a solution, which can dynamically reduce the mismatch between the demand and supply sides of the UAE labor market.

The author in [23] identifies solutions that address the study's limitation by [3]. In addition, [23] made a case for the iLMIS's values which are achievable if employment services and statistical functions are allowed to interact and dynamically benefit from each other. However, [23] did not look at the proposed solution's architecture, iLMIS, from its technological perspective for feasible implementation. The study was limited to a statement highlighting the need to identify the technological components that ensure offering user-centric labor market information and services to all stakeholders. This limitation is addressed in the current paper by proposing the utilization of disruptive technologies components in the implementation of iLMIS. The offered components cover the technology part of implementing the iLMIS; this includes IT infrastructure, data collection tools, and technologies for processing and disseminating labor market information.

It is necessary to mitigate the skills and educational mismatch problem in the UAE as it can lead to employee productivity issues, wage dissatisfaction, and other unfavorable labor market outcomes [32-34]. Besides, another fact that the COVID-19 pandemic has further deepened this problem in UAE and other countries across the globe. It is required to promptly provide a new approach to manage the current labor market eco-system effectively and elevate its role as the main component of its economic development planning over the coming few years. The new approach should consider connecting all the labor market's stakeholders, the workforce and representatives of the demand, the supply, and the regulator sides, as the data exchange mechanisms would include input from them. The collected data shall be processed and analyzed with only the relevant information being extracted and targeted to the end-users.

Fig. 6 illustrates a system design architecture that complements the [23] study's outcomes and proposes implementing an iLMIS smart platform enabled by advanced technological components outlined in the earlier discussion (machine learning, AI, blockchain, big data analytics, and cloud computing).

By adopting the proposed implementation approach, all the labor market stakeholders will be connected dynamically through a complex, intelligent, and automated system, as depicted in Fig. 6. The proposed iLMIS smart platform oversees the entire life cycle of the education-to-employment journey, ensuring more splendid orchestration between various stakeholders enabled by machine learning. It will also provide a new customized experience, information, and actions needed for different users as enabled by big data analytics. In addition, the proposed iLMIS smart platform will operate as a smart environment that is developed through the integrating of various environments using the power of IoT. Moreover, the smart platform will also support real-time stakeholder response, data computing, and data storage using cloudcomputing technologies. Furthermore, as blockchain technologies will enable the smart platform, the transaction records' traceability will be facilitated, extending the collaboration between stakeholders efficiently. Finally, as AI will enable the smart platform, smart decision-making will be facilitated, and decisions driven by real-time data will be carried out.

Therefore, in line with the insights presented above, the current paper proposes a strategic course of actions to solve the UAE labor market's mismatch problem. The UAE may consider a better way to manage the labor market by implementing an iLMIS supported by disruptive technologies (Machine Learning, AI, Blockchain, Internet of Things, Big Data Analytics, and Cloud Computing). Hence, the implemented iLMIS solution can effectively handle the upcoming challenges in the UAE labor market amid the COVID-19 pandemic. This course of actions shall deliver at a low cost a feasible solution that is easy to implement, efficient, reliable, robust, and user-friendly. In addition to that, it shall allow all stakeholders to interact and dynamically benefit from each other. As a result, the iLMIS shall offer more adapted services to suit better employers and workers, as well as the data collected through the management of services to construct more accurate and predictive models of the UAE labor market performance. Table II outlines the SWOT analysis for the proposed iLMIS implementation approach towards reducing the skills and educational mismatch evident in the UAE labor market.

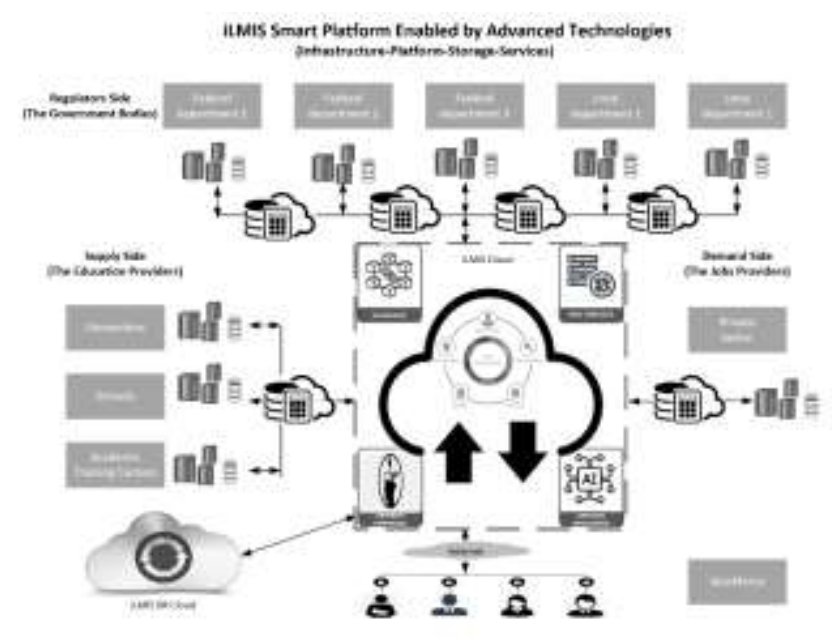

Fig. 6. System Design Architecture. 


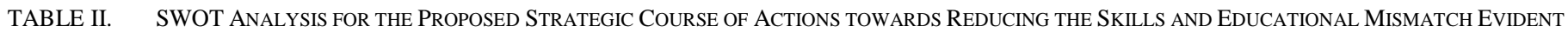
IN THE UAE LABOR MARKET

\begin{tabular}{|c|c|}
\hline SWOT & Remarks \\
\hline Strength & $\begin{array}{l}\text { 1. Mismatch phenomena discovery and management in a cost-effective and time-efficient approach. } \\
\text { 2. Quick prediction and propagation analysis of the mismatch phenomena while limiting human intervention. } \\
\text { 3. On-time detection of the demand-supply imbalance as it happens to result in faster analysis and prompt corrective actions. } \\
\text { 4. It is a fast, cost-effective, and self-diagnosis approach for the root causes of the dynamic mismatch phenomena, enabling } \\
\text { stakeholders to focus their operation and resources while contributing to the solutions. } \\
\text { 5. It leads to discovering permanent, cost-effective solutions for the mismatch phenomena and contamination of its spread. } \\
\text { 6. Supports lessens the economic buzzes regarding labor market issues with automated approaches using artificial intelligence. } \\
\text { 7. Offers time-efficient and automated responses that are available } 24 \mathrm{x} 7 \text { for all stakeholders, which endure; secure, dynamic, and robust } \\
\text { mismatch solution and prevention mechanisms. } \\
\text { 8. Smart problem-solving techniques ensure efficient utilization of the interdependent systems' resources and effective diagnosis } \\
\text { without affecting individual stakeholders' operations. } \\
\text { 9. Provides effective monitoring of the current status of the mismatch phenomena through; ensuring gathering the latest updates and } \\
\text { integrating with several heterogeneous sources to a single platform. } \\
\text { 10. Effective data exchange mechanism ensures the availability of all essential data to all stakeholders as needed. }\end{array}$ \\
\hline Weakness & $\begin{array}{l}\text { 1. Relying heavily on the current UAE labor market information patterns may generate biases concerned with the incoming drifting } \\
\text { data. } \\
\text { 2. Proposed disruptive technologies approaches require heavy computation resources to detect the mismatch phenomena that might not } \\
\text { be available to the UAE labor market stakeholders. } \\
\text { 3. Wrong pattern discovery may lead to severe results in the real national labor market; therefore, the high quality of data is required to } \\
\text { avoid the spread of false information and the generation of unnecessary economic fear situations. } \\
\text { 4. The required resources to design, deploy and operate the solution may not be available in the country. } \\
\text { 5. The solution is challenged, as the processing of the official language, Arabic, is required to recognize fake news. } \\
\text { 6. Several trials would consume a massive amount of resources, efforts, time, and financial support for such an innovative way. } \\
\text { 7. Solution adaptability is a critical issue for national governing bodies as it requires a central-management, overarching infrastructural } \\
\text { which changing the current roles and responsibilities of the individual shareholders. } \\
\text { 8. The involvement of all labor market stakeholders and their technological awareness is needed for more accurate solution results. } \\
\text { 9. The solution depends on the authorized sources of information; hence chances of duplicate information are high and micro-level } \\
\text { analysis is required for all the labor market stakeholders' data. } \\
\text { 10. The solution may raise security concerns and be incompatible with the current labor market stakeholders' IT infrastructures and } \\
\text { systems. }\end{array}$ \\
\hline Opportunities & $\begin{array}{l}\text { 1. The prediction and propagation analysis will minimize the amount of economic loss based upon the current situation of the mismatch } \\
\text { phenomena in the UAE and lead to the generation of the follow-up plans to mitigate the early planning issues containing its spread. } \\
\text { 2. Disruptive techniques support the central analysis procedure with automated approaches that promptly detect the mismatch } \\
\text { phenomena and spare more time to assess alternative solutions instead of distributed and interlinked analysis. } \\
\text { 3. AI-based approaches for solution discovery can be executed without causing any harm to the country's economy. } \\
\text { 4. Provides a chance to the labor market stakeholders to focus more on strategies, policies, and legislations making for proper operation } \\
\text { of the complex solution and encourages them to develop better behaviors concerning cross-work and data sharing to achieve } \\
\text { common goals and targets. } \\
\text { 5. Protects from economic infodemics by implementing better learning algorithms for more robust innovative solutions and monitoring } \\
\text { mechanisms for the mismatch phenomena. } \\
\text { 6. Fortifies the world economies with more promising and robust solutions for the ever known mismatch phenomena and encourages } \\
\text { 0\% unemployment rate economy and opening new avenues for; smart-space infrastructure development, labor relation standard and } \\
\text { rights, smart working environment, automated surveillance with limited human resources. } \\
\text { 7. It increases the effectiveness and transparency through; technological advancements, platform compatibility, and micro-level } \\
\text { analysis. } \\
\text { 8. It permits the high potential for broader application across various countries. } \\
\text { 9. Will allow companies to gain cross-country access to hiring individuals remotely with relevant and matched skills and vice versa. } \\
\text { 10. The disruptive technologies have proven record for being feasible and thriving in implementing and operating such solutions. }\end{array}$ \\
\hline Threats & $\begin{array}{l}\text { 1. Security concerns related to sharing private information globally with the possibility of false-negative predictions could generate an } \\
\text { unnecessary panic situation. } \\
\text { 2. The AI approaches have a percentage of error; therefore, false detection of the mismatch phenomena could fire back, and hence } \\
\text { human supervision of the results is required before sharing labor market information in the public platform. } \\
\text { 3. The solution's discovery simulations may deviate from the real world and cause a national economic disturbance. } \\
\text { 4. The shared information may raise the anxiety level among individuals or organizations impacted by unwanted executed actions, and } \\
\text { as a result, they may share fabricated information on public platforms that could mislead the nation. } \\
\text { 5. The high acceptance resistance to handling the mismatch phenomena via technology-based solutions even if the solution shall } \\
\text { provide information of public concern. } \\
\text { 6. Novel discovered actions, untested, might generate undesirable impacts on the economy. } \\
\text { 7. The technology-based readiness of economic disruption may increase the unemployment ratio. } \\
\text { 8. There is a potential for too much dependency on the technologies, and hence malfunctioning of such solution, privacy, trust, and } \\
\text { 9. Decurity issues become significant concerns. } \\
\text { continue coming into the picture. } \\
\text { 10. False indicators may cause unnecessary economic disruption; therefore, the solution, design, implementation, supervision, and } \\
\text { maintenance should be handled with profound attention. }\end{array}$ \\
\hline
\end{tabular}




\section{Challenges}

Several challenges can limit implementing of the proposed strategic course of actions, iLMIS enabled by disruptive technologies, to solve the skills and educational and educational mismatch problem in the UAE.

One of the core challenges is related to regulatory challenges whereby the use of disruptive technologies in the labor market sector to resolve skills and educational mismatch should be considered carefully with the UAE's regulatory laws. While these technologies bring benefits, it also poses legal and regulatory issues as, currently, the accountability of the education-to-employment eco-system is distributed across multiple parties. For example, in the case of using blockchain technologies, it will be essential to consider what law might apply and the potential risks to be mitigated. Similarly, in the case of using AI, creating national standard norms of legal and governance models may be considered more contented to dictate $\mathrm{AI}$ usage in the UAE labor market. In addition to that, government regulators' privacy considerations, private organizations, and individuals might prevent access to data, which is needed for the proposed strategic course of actions to be successful.

Another challenge to implementing iLMIS technologyenabled is that there is no unified data center in the UAE or a linked structure that can provide access to information required from or for the parties involved. A lack of central unified databases is a critical challenge to solve the issue of mismatch. Most of the current labor market information databases are collected from several sources; however, it is not sufficient for iLMIS to create more significant impacts to solve a complex problem. On a broader scale, most of the time, countries are reluctant to share data; therefore, it is challenging to understand proactive measures' principal characteristics without local and global data availability.

\section{FUTURE GUIDELINES}

The future guidelines are based on the unanticipated risks that affect the world economies in 2020 due to the COVID-19 pandemic, which seems to be an unending pandemic. Thus, there is an urgency to accelerate liable action plans to overcome the deeper mismatch problem during the crisis, have a solution for this problem, and ensure labor equilibrium for a better UAE economy for the generations to come. This complex problem demands a severe contribution from policymakers and regulators to demonstrate legal plausibility, ethical soundness, and effectiveness of deploying a national iLMIS enabled by emerging, future, and disruptive technologies under the current time pressure. The accelerated action plan needs to consider three main stages that must be executed consecutively: acknowledging, reinforcing, and re-engineering.

The first stage is acknowledging. It is essential to admit the prevalence of the mismatch problem in the national labor market and act decisively to have the best possible solution. Such a complex solution is feasible to be implemented and operated based on the existing disruptive technologies to resolve the skills and educational mismatch issue amid the COVID-19 pandemic. This stage shall support continuity, productivity, and prosperity of the UAE's economy and gain the buy-in of the labor market's stakeholders to move towards the success of such a solution.

The second stage is reinforcing. Once acknowledgment of the problem and the need for an urgent solution is realized, the reinforcing stage needs to be covered. It is required to have sufficient time to identify the structure of the iLMIS solution and the disruptive technologies components required for its implementation and operation. It is equally vital to realign priorities and allocate resources to assess each of the emerging technologies to ensure a balance between costs and benefits while identifying the technologies to be used to build the new solution (iLMIS). The next step is to strengthen and build the identified technological capabilities that will lead to efficient automation for the new solution (iLMIS) processes and workflows that encounter the mismatch problem challenges amid COVID-19. It is indicated that stand-alone technologies cannot add value by themselves; however, they can play a prominent role in implementing and operating a solution. Therefore, it is crucial to identify the possible new solution (iLMIS) topology and the needed disruptive technological solutions in the labor market context. Moreover, it is equally essential to ensure proper design, policies, and regulatory measures are put in place for a successful implementation of this solution.

The third stage is the re-engineering. Once a prompt response to solve the problem is taken, the re-engineering stage is initiated. The new solution (iLMIS) shall impose genuine and dynamic collaboration between the labor market's stakeholders to change their current operations models. It is mandatory to develop a framework that leads the shift from the current eco-system to the new eco-system powered by the new solution (iLMIS). Serious effort is required to review and assess the current eco-system and its technology-based solutions to develop the new solution (iLMIS). This effort must include the current strategies, plans, infrastructure, systems, laws, rules, and guidelines to reframe the existing setups and design the new setups to resolve the stated issue. After achieving that, proper time needs to be allocated to drive rapid growth and sustainable development of the new solution (iLMIS) to gain momentum in all labor market sectors and steer the economic wheel towards a better future of work in the UAE labor market. This stage shall support guiding the successful implementation of the new solution (iLMIS).

\section{CONCLUSION}

The paper first introduced the two categories of the concept of disruptive technologies (human-centric and smart-space). This introduction was followed by an explanation of the LMIS concept and its types. Then the paper has portrayed the mismatch outlook in the UAE labor market amid COVID-19 and the need for iLMIS to resolve this issue. The followed section highlighted the current trend for iLMIS implementation and its limitations. Hence, a proposition was made for implementing an iLMIS enabled by disruptive technologies components as one of the immediate courses of action to solve the mismatch problem in the UAE labor market. The same section included a SWAT analysis for the proposed approach. The paper then covered the foreseen challenges found at two levels in the UAE labor market; regularity and decentralized 
ownership of data. Lastly, future directions have been presented to highlight research areas within this body of knowledge.

The implementation approach proposed is a novel contribution to resolve the issue of skills and educational mismatch evident in the UAE labor market and grew deeper amid COVID-19. The paper highlights the potential for leveraging six disruptive technologies in implementing an iLMIS to provide a dynamic linkage and facilitate orchestration between and across various labor market stakeholders' groups. The leveraging of disruptive technologies towards solving the mismatch problem was mostly missing from past researches, and the current study bridges this gap. The proposed approach is dictated by the complex nature of the skills and educational mismatch problem and the urgent need for efficient development of 21st-century skills. It is believed that with the vast amount of data required to resolve the aforementioned problem, which is sourced by multistakeholders, the need for using iLMIS enabled by disruptive technologies is necessary to facilitate its mitigation.

\section{REFERENCES}

[1] A. Tamimi and C.-E. Kressner, "The Gap between Education, Talent, and Technology in the UAE | Lexology," www.lexology.com, 2016. https://www.lexology.com/library/detail.aspx?g=05fd91cd-45d8-40269fde-ec7ab5fa2075 (accessed 22 February 2021).

[2] British Council, "Future skills supporting the UAE's future workforce," 2014. [Online]. Available: https://www.britishcouncil.ae/sites/default /files/bc_futureskills_english_1mar18_3.pdf.

[3] Goher, G., Masrom, M., Amrin, A., \& Abd Rahim, N. "UAE's Labor Market Snapshot | Skills and Educational Mismatch During Industry 4.0", International Journal of Recent Technology and Engineering, vol. 8, pp. 1332-1340, 2020. https://doi.org/10.35940/ijrte.f7626.038620.

[4] Gartner, 2020. "Top 10 Strategic Technology Trends for 2020". 2020. [Online]. Available: https://www.gartner.com/en/publications/top-techtrends-2020.

[5] van der Aalst, Martin Bichler, and Armin Heinzl, "Robotic process automation", 2018

[6] Dunie, R., Schulte, W. R., Cantara, M., \& Kerremans, M, "Magic Quadrant for intelligent business process management suites", 2020.

[7] Farshid Mana, Jeannette Paschen, Theresa Eriksson, and Jan Kietzmann. 2018. Go boldly!: Explore augmented reality (AR), virtual reality (VR), and mixed reality (MR) for business. Business Horizons 61, 5 (2018), 657-663.

[8] Milgram Paul and Fumio Kishino. 1994. A taxonomy of mixed reality visual displays. IEICE TRANSACTIONS on Information and Systems 77, 12 (1994), 1321-1329.

[9] Crowell Philip, Gregory Kanagaki, Meghan O'donovan, Courtney Haynes, Joon-hyuk Park, Jennifer Neugebauer, Edward Hennessy, Angela Boynton, Blake Mitchell, Andrew Tweedell, and Henry Girolamo. "Methodologies for Evaluating the Effects of Physical Augmentation Technologies on Soldier Performance Methodologies for Evaluating the Effects of Physical Augmentation Technologies on Soldier Performance," 2018.

[10] Cinel Caterina, Davide Valeriani, and Riccardo Poli. "Neurotechnologies for Human Cognitive Augmentation: Current State of the Art and Future Prospects." Frontiers in Human Neuroscience, vol. 13, 2019.

[11] Veloso Bruno M, Fátima Leal, Benedita Malheiro, and Juan Carlos Burguillo, "A 2020 perspective on Online guest profiling and hotel recommendation: Reliability, Scalability, Traceability and Transparency". Electronic Commerce Research and Applications vol.40, 2020.

[12] Haroon, M. Basharat, A. M. Khattak, and W. Ejaz, "Internet of Things Platform for Transparency and Trace-ability of Food Supply Chain.” In
2019 IEEE 10th Annual Information Technology, Electronics and Mobile Communication Conference (IEMCON), pp. 0013-0019, 2019.

[13] El-Fakih Khaled, Teruhiro Mizumoto, Keiichi Yasumoto, and Teruo Higashino, "Energy aware simulation and testing of smart-spaces." Information and Software Technology, vol.118, 2020.

[14] Honging Ji, Osama Alfarraj, and Amr Tolba. 2020. Artificial Intelligence-Empowered Edge of Vehicles: Architecture, Enabling Technologies, and Applications. IEEE Access 8 (2020), 61020-61034.

[15] Langley David J, Jenny van Doorn, Irene CL Ng, Stefan Stieglitz, Alexander Lazovik, and Albert Boonstra. 2020. The Internet of Everything: Smart things and their impact on business models. Journal of Business Research (2020).

[16] Fabiano Nicola. 2017. Internet of Things and blockchain: legal issues and privacy. The challenge for a privacy standard. In 2017 IEEE International Conference on Internet of Things (iThings) and IEEE Green Computing and Communications (GreenCom) and IEEE Cyber, Physical and Social Computing (CPSCom) and IEEE Smart Data (SmartData). IEEE. 727-734.

[17] S. Araz, "The UAE eyes AI supremacy: A key strategy for the 21st century," Middle East Institute, 2020. https://www.mei.edu/publications /uae-eyes-ai-supremacy-key-strategy-21st-century (accessed 22 February 2021).

[18] UAE Government, "Blockchain in the UAE government - The Official Portal of the UAE Government," u.ae, 2021. https://u.ae/en/about-theuae/digital-uae/blockchain-in-the-uaegovernment\#: :text=The\%20UAE\%20Government $\% 20$ adopted $\% 20 \mathrm{blo}$ ckchain $\% 20$ technology $\% 20$ in $\% 20$ conducting $\% 20$ its $\% 20$ transactions.\&t ext=The \%20Emirates\%20Blockchain\%20Strategy\%202021\%20aims $\% 2$ 0to\%20capitalise\%20on\%20the (accessed 22 February 2021).

[19] Deloitte, "Big Data in the GCC," Deloitte, 2019. https://www2.deloitte. com/ye/en/pages/about-deloitte/articles/revolution/big-data-gcc.html (accessed 22 February 2021).

[20] B. McKenzie, "UAE Regulates Internet of Things | Insight | Baker McKenzie," www.bakermckenzie.com, 2019. https://www.bakermcke nzie.com/en/insight/publications/2019/05/uae-regulates-internet-ofthings (accessed 22 February 2021)

[21] A. Buller, "Cloud computing surges in the UAE in 2019," ComputerWeekly.com, 2019. https://www.computerweekly.com/news /252475177/Cloud-computing-surges-in-the-UAE-in-2019 (accessed 24 November 2020)

[22] Green, F. and Zhu, Y, "Overqualification, job dissatisfaction, and increasing dispersion in the returns to graduate education," Oxford economic papers, vol.62, pp.740-763, 2010.

[23] National Skill Development Corporation (NSDC). "Concept paper on labor market information system: an Indian perspective," 2011. http://www.tsscindia.com/media/1433/concept-paper-on-lmis.pdf.

[24] Sparreboom, T., \& Powell, M. Labor market information and analysis for skills development (No. 994340413402676). International Labor Organization. 2009.

[25] J. Connell et al., "The importance of content and face validity in instrument development: lessons learned from service users when developing the Recovering Quality of Life measure (ReQoL)," Quality of Life Research, vol. 27, no. 7, pp. 1893-1902, Apr. 2018, DOI: 10.1007/s11136-018-1847-y.

[26] Khaleej Times, "49\% of UAE respondents believe 'skills gap' exists," Khaleej Times, 2017. https://www.khaleejtimes.com/49-of-uaerespondents-believe-skills-gap-exists (accessed 14 February 2020).

[27] McGuinness, S., Pouliakas, K., \& Redmond, P. "How useful is the concept of skills mismatch?." 2017.

[28] Di Stasio, V. "Diversion or safety net?' Institutions and public opinion on vocational education and training". Journal of European Social Policy, vol. 27, pp.360-372, 2017.

[29] Nguyen, T. T., "Artificial intelligence in the battle against coronavirus (COVID-19): a survey and future research directions". Preprint, vol.10, 2020.

[30] Jumper, J., Tunyasuvunakool, K., Kohli, P., Hassabis, D. and the AlphaFold Team (2020). Computational predictions of protein structures associated with COVID-19, DeepMind website, 5 March 2020, 
https://deepmind.com/research/opensource/computational-predictionsof-protein-structures-associated-with-COVID-19.

[31] Etzioni, O., \& DeCario, N. "AI can help scientists find a COVID-19 vaccine". WIRED. 28 March 2020.

[32] Grunau, P., "The impact of overeducated and undereducated workers on firm-level productivity-First evidence for Germany. In Forthcoming, Institute for Employment Research (IAB), Nuremberg, Germany". Paper presented at the Workshop Firm-level Analysis of Labor Market Issues, Université Catholique de Louvain, Belgium, 2014.

[33] Mahy, B., Rycx, F. and Vermeylen, G., "Educational mismatch and firm productivity: Do skills, technology and uncertainty matter?" De Economist, vol.163, pp.233-262, 2015.

[34] Allen, J. and Van der Velden, R., "Educational mismatches versus skill mismatches: effects on wages, job satisfaction, and on-the-job search," Oxford economic papers, vol. 53, pp.434-452, 2001.

\section{AUTHORS' PROFILE}

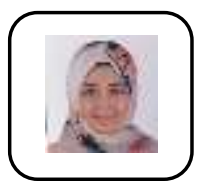

Eng. Ghada Goher is a researcher Ph.D. student at Razak Faculty of Technology and Informatics, previously known as Razak Faculty of Engineering and Advanced Technology, Universiti Teknologi Malaysia. Because she believes that "Life itself is your teacher, and you are in a state of constant learning. Bruce Lee", she is starting her researching work with $27+$ years of comprehensive large-scale management experience in diversified areas of the ICT Industry. She is known for developing strategies, policies, procedures, and operation models. She has proven records of accomplishment of government services providing model excellence. She was a pioneer in integrating the franchising techniques with the government service providing models. She possesses substantial experience in UAE and Egypt, specifically in the following business areas; Immigration, Border Control, Labor, Health, Airline, Banking, and Courts. She holds an Engineering Bachelor, Software Development diploma, Technical Professional Diploma, MCSE Certification, PMP Certification, Information Technology MSc, and Master of Business Administration (MBA). She was a recipient of various awards such as; The Technical Excellency of the year from Microsoft Egypt "System Architect." She has been an active member of the Project Management Institute (PMI), Arabian Gulf Chapter, and UAE Chapter.

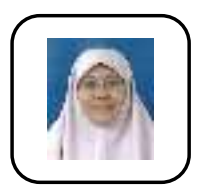

Prof. Dr. Maslin Masrom is an Associate Professor at Razak Faculty of Technology and Informatics, previously known as Razak Faculty of Engineering and Advanced Technology, Universiti Teknologi Malaysia (UTM). She received her Bachelor in Computer Science from Universiti Teknologi Malaysia. She received her Master of Science in Operations Research from Western Michigan University, the USA, and a Ph.D. in Information Technology/Information System Management from Universiti Putra, Malaysia. Her teaching experiences have been focusing on operations research/operations management, IT/IS management, knowledge management, and ethics in computing. Her current research interest includes it-adoption, egovernment, technology management, information security management, women and technologies, cloud computing, structural equation modeling, and creativity and innovation management. She was a recipient of various awards, including Best Paper Award, Knowledge Management International Conference, Best Publishing Award Multimedia and Communication
Technology, McGraw-Hill Publishing Best Paper Award in Operations Management / Management Information Systems, Universiti Teknologi Malaysia Excellence Service Award, Universiti Teknologi Malaysia Distinction Service Award. She was appointed as a Visiting Professor at many International Engineering and Technology universities. She has chaired numerous technical programs and has been an active member of various national and international technical committees.

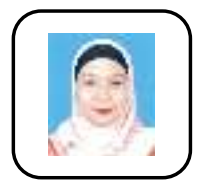

Prof. Dr. Astuty Amrin is an Associate Professor at the Department of Engineering, Razak Faculty of Technology and Informatics, previously known as Razak Faculty of Engineering and Advanced Technology, Universiti Teknologi Malaysia (UTM). Currently, she is also the Dean of Razak Faculty of Technology and Informatics UTM. She received her Bachelor in Materials Eng. (pioneer batch) from Universiti Sains Malaysia, MSc in Corrosion Sc. and Eng. from UMIST, UK and Ph.D. in 2005. Her teaching experiences have been focusing on technology management, creativity, and innovation management, maintenance management, research methodology, innovation \& new product development, materials science, and technology. She was a recipient of various awards, including Award of Excellence for Active Blended Learning in Technology Management course. Her research interest is devoted to Materials Engineering, specifically on high-temperature oxidation of alloys, compositional modification of newly developed $(\alpha+\beta)$ Ti-Alloys, developing accelerated corrosion test procedures for Malaysia automotive industry, ultraviolet treatment for microbially-influenced corrosion of steels, rejuvenation of $\mathrm{Ni}-\mathrm{Cr}$ superalloy turbine blade. She was appointed as a Visiting Professor at Sudan University of Science and Technology in February and December 2016. She has also been appointed as a Visiting Professor at the King Mongkut's University of Technology Thonburi, Bangkok, Thailand, since 2015 and panel of experts for MSc in Corrosion Engineering program for Universiti Teknologi Petronas. She has chaired numerous technical programs and has also been an active member of various national and international technical committees, advisory boards, program committees, and editorial boards.

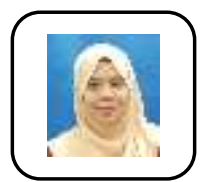

Dr. Noorlizawati Abd Rahim is a senior lecturer at the Science, Management \& Design Department, Razak Faculty of Technology and Informatics, previously known as Razak Faculty of Engineering and Advanced Technology, Universiti Teknologi Malaysia. Her teaching focuses on entrepreneurship, quantitative data analysis, and semiconductor materials engineering. Her research interests are in the areas of technology, entrepreneurship, and entrepreneurship education. She is a member of the IEEE Technology and Engineering Management Society and Malaysia Nanotechnology Association. Before the faculty appointment, she had industrial experiences in chipset design and development, semiconductor manufacturing, and technology commercialization from Intel, Freescale Semiconductor, and NanoMalaysia. She received her BEng in Electrical \& Electronic Engineering from Cardiff University, MSc in Nanotechnology from University College London (UCL), and Ph.D. in entrepreneurship from Universiti Teknologi Malaysia. Noorlizawati was the recipient of the 2017 Innovation Book Award by Malaysian Technology Development Corporation, the 2012 MSc Nanotechnology Achievement Award from UCL, and the 2008 IET Electrical \& Electronic Engineering Prize. 